\title{
ANÁLISE COMPARATIVA DO DESEMPENHO TEXTUAL DE ESTUDANTES DE QUARTA E QUINTA SÉRIES DO ENSINO FUNDAMENTAL COM E SEM QUEIXA DE DIFICULDADES NA LINGUAGEM ESCRITA
}

\author{
Comparative analysis of textual performance in student \\ of fourth and fifth grade of elementary school with and without \\ complaint of disabilities in writing language
}

\author{
Vanessa Deuschle-Araújo (1), Ana Paula Ramos de Souza ${ }^{(2)}$
}

\begin{abstract}
RESUMO
Objetivo: comparar o desempenho na produção textual e a compreensão leitora de estudantes de quarta e quinta séries do ensino fundamental, com e sem queixa de dificuldades de linguagem escrita, relacionando-as às práticas de letramento experenciadas por esses estudantes. Métodos: foram avaliados 21 pré-adolescentes, de quarta e quinta série de duas escolas públicas, com queixa de dificuldade de linguagem escrita e 21 controles da mesma sala de aula, quanto à produção textual, compreensão textual e práticas de letramento. As produções textuais foram avaliadas segundo o protocolo de níveis textuais. Resultados: não há diferença estatística entre os grupos de estudo e controle, em ambas as séries, na habilidade de compreensão textual. Em relação à produção textual, na quarta série os itens que apresentaram diferença estatística foram: situacionalidade, aceitabilidade, repetição, progressão e intencionalidade. Já na quinta série, os itens alterados foram a aceitabilidade e a progressão. Todos os sujeitos apresentaram práticas de letramento insuficientes. Conclusões: houve diferença estatística entre o grupo controle e de estudo em algumas categorias textuais, sobretudo, aceitabilidade e progressão. De um modo geral, ambos os grupos apresentaram desempenhos textuais abaixo do esperado para sua escolaridade, fato que parece estar relacionado a práticas de letramento insuficientes, tanto na escola como no ambiente familiar.
\end{abstract}

DESCRITORES: Transtornos de Aprendizagem; Leitura; Distúrbios de Aprendizagem

\section{INTRODUÇÃO}

Sabe-se que na realidade brasileira e latinoamericana ${ }^{1}$ muitas crianças não conseguem apropriar-se da linguagem escrita de modo a

(1) Fonoaudióloga da Secretaria Municipal de Saúde de São Francisco de Assis, RS; Mestre em Distúrbios da Comunicação Humana pela Universidade Federal de Santa Maria, UFSM, RS.

(2) Fonoaudióloga; Professora Adjunta do Programa de PósGraduação em Distúrbios da Comunicação Humana da Universidade Federal de Santa Maria, UFSM, Santa Maria, RS; Doutora em Linguística Aplicada pela Pontifícia Universidade Católica do Rio Grande do Sul.

Conflito de interesses: inexistente
atribuir-Ihe função social e passam a ver a mesma como algo impossível de ser apreendido. Alguns autores afirmam ${ }^{2}$ que essa realidade é proveniente de práticas de normatização da língua que geram um processo de exclusão crescente em relação ao processo de letramento e apropriação da linguagem escrita. Ressaltam que a resposta a este fato não tem ocorrido de modo satisfatório na escola, bem como na clínica. Na escola porque não há uma iniciativa e suporte para a mudança e, muitas vezes, nem a percepção de que algo precisa mudar em termos pedagógicos. Já na clínica, a depender da concepção de linguagem, pode haver foco nos aspectos intrínsecos do sujeito em detrimento dos aspectos pedagógicos que são, sem 
dúvida, geradores de dificuldades e no caso de "verdadeiros" distúrbios orgânicos, como a dislexia, apresentar-se-iam como um obstáculo a mais ao aprendizado ${ }^{3-5}$.

Outro aspecto observado no sistema educacional que justifica pensar na presença de práticas de letramento inadequadas é a quase ausência de trabalho textual na escola, com um foco importante na exigência da forma escrita, sem, contudo, a oferta necessária de oportunidades de contato com o texto ${ }^{6}$. A Linguística do Texto oferece, já a alguns anos, subsídios importantes que não se refletem nos procedimentos de ensino, nem nos de avaliação escolar. Na Fonoaudiologia, esse aspecto também pode ser observado quando a maior parte dos estudos na área de distúrbios específicos da linguagem escrita tomam como unidade a palavra ${ }^{4-8}$ fato se reflete numa ausência de qualquer classificação que considere dificuldades na construção do texto ${ }^{9}$. No entanto, já existem estudos clínicos que utilizam o texto como unidade de avaliação e terapia ${ }^{10-13}$.

A visão de gênero textual/discursivo ${ }^{14}$ resgatou, junto a alguns fonoaudiólogos e educadores, o texto como unidade de trabalho no processo de letramento ${ }^{3,15}$. Ela se fundamenta na percepção de que as pessoas fazem algo com a linguagem e que necessitam ter o que dizer, para quem dizer e ter os recursos linguísticos necessários para que isso ocorra. O texto é a unidade de comunicação oral e escrita no cotidiano dos interlocutores que se materializa em diversos gêneros como conversa face-a-face, telefonema, entrevista oral e escrita, palestras, artigo cientifico, artigo de jornal, texto opinativo, bula de remédio, receita de alimentos, entre outros. Tal perspectiva, também, é adotada nos padrões curriculares nacionais para o ensino da língua portuguesa. No entanto, ainda não se constituiu numa realidade escolar ${ }^{16}$. Um grupo de autores brasileiros propõe ${ }^{17}$, inseridos em uma perspectiva sócio-interacionista, uma grade curricular como sugestão para o trabalho com gêneros discursivos de primeira a quarta séries.

Há ainda, na literatura educacional, o reconhecimento de que não há mudanças importantes nas práticas de letramento escolar, como também de que outros fatores, como nível sóciocultural e gênero, possam interferir na avaliação do professor 18,19, produzindo desencontros entre 0 desempenho observado pelo aluno e a nota atribuída pelo professor ${ }^{20}$.

A passagem do segundo para o terceiro ciclo escolar foi escolhida, para esta pesquisa, por se tratar de um momento em que o texto começa a ser mais focado como unidade na produção escolar, já que o processo de alfabetização deveria estar concluído e a aquisição da escrita deveria continuar através do domínio progressivo de categorias textuais, bem como pelo acesso a distintos gêneros discursivos.

Dentro do exposto acima, o presente trabalho tem por objetivo comparar o desempenho textual e a compreensão leitora de estudantes de quarta e quinta séries do ensino fundamental, com e sem queixa de dificuldades de linguagem escrita, relacionando-as às práticas de letramento experenciadas por esses estudantes.

\section{MÉTODOS}

A presente pesquisa é composta de 42 sujeitos, alunos de quarta e quinta séries do ensino fundamental de duas escolas municipais da cidade na qual o estudo foi realizado, sendo 21 sujeitos do grupo de estudo (GE), identificados por seus professores de língua portuguesa como apresentando Dificuldade/Distúrbio de Leitura e Escrita (DLE) e seus respectivos controles. O grupo controle (GC) foi formado por 21 sujeitos sem queixa de DLE, da mesma escola, sala e série do sujeito dito com DLE, mas que segundo o professor poderia ser considerado um "bom aluno", sendo que ambos os grupos foram avaliados no período de abril a julho de 2008. As escolas participantes da pesquisa foram selecionadas por manifestarem a necessidade de intervenções especializadas a fim de melhorar o aprendizado de seus alunos.

Os pais foram convidados para uma entrevista na qual foram explicados os objetivos, benefícios, a ausência de riscos e demais aspectos éticos da pesquisa. Estando de acordo com a realização da pesquisa, os pais assinaram o Termo de Consentimento Livre e Esclarecido, permitindo que seu filho participasse deste estudo. Após, os pais participaram de uma entrevista contendo perguntas sobre as práticas de letramento familiar e a função social da escrita atribuída por eles.

Fizeram parte dessa pesquisa todos os sujeitos identificados por seus professores como apresentando DLE e seus respectivos controles, alunos sem queixa de dificuldades no domínio da linguagem escrita, desde que os pais estivessem de acordo, assinassem o Termo de Consentimento Livre e Esclarecido e os sujeitos completassem todas as avaliações propostas.

Descartaram-se da pesquisa os sujeitos que os pais não assinaram o Termo de Consentimento Livre e sclarecido, além aqueles que apresentaram distúrbios de escrita/aprendizagem relacionados a grandes transtornos do desenvolvimento, tais como deficiência mental, paralisia cerebral, autismo, psicose, ou mesmo a déficits sensoriais como a 
surdez e cegueira, segundo informações fornecidas pela escola.

Além disso, também foram excluídos da pesquisa os sujeitos que não completaram as avaliações ou abandonaram a escola no período da coleta.

Os dados em relação à compreensão textual foram coletados através da leitura e compreensão de um texto com resposta a questões relativas ao mesmo. O texto "Negrinho do Pastoreio" foi retirado de uma cartilha programada para a quinta série e possui temática folclórica da região na qual ocorreu a pesquisa. Sua compreensão foi testada através de 06 questões (03 objetivas e 03 dissertativas). 0 número de respostas corretas foi comparado entre os grupos a partir de números absolutos e com testes estatísticos. Para os alunos da quarta série, o texto abordava a temática da água e, também, foi retirado de uma cartilha programada para a série em questão. Duas questões eram objetivas e se relacionavam mais à memorização de dados do texto, enquanto três questões eram dissertativas, as quais demandavam um pouco mais de reflexão, especialmente a última. Os alunos foram convidados a ler o texto silenciosamente, coletivamente, e a assinalar as questões que julgassem corretas a cada questão durante um tempo aproximado de 40 minutos.

A produção textual foi realizada de dois modos: pela produção de um texto autobiográfico e um texto sobre violência, com duração de, aproximadamente, 30 minutos cada. O tema autobiográfico foi escolhido pela pesquisadora por se entender que seria bem aceito pelos estudantes e que teriam desejo e condições de falar de si próprios. Já o tema sobre a violência foi escolhido pelos professores dos alunos por estar muito próximo da realidade em que vivem e por ser temática de interesse na mídia em função do Caso Isabela. O envolvimento dos sujeitos com o tema era visível e havia ocorrido debates em sala de aula a respeito, o que talvez atuasse como facilitador na produção textual. Este tema atenderia ao que os autores denominam de condições de produção ou situacionalidade ${ }^{21,22}$.

As produções escritas foram classificadas a partir de categorias textuais ${ }^{21}$, conforme a Figura 1.

Os textos foram classificados pela primeira autora desse trabalho, segundo os níveis de categorias textuais ${ }^{21}$, e conferidos pela segunda autora do trabalho.

\begin{tabular}{|c|c|}
\hline \multicolumn{2}{|r|}{ Níveis de Textualidade elaborados por Lubian (2007) } \\
\hline \multirow{3}{*}{ I - Intencionalidade } & 1.1 - O texto é neutro não demonstrando nenhuma intencionalidade. \\
\hline & $1.2-O$ texto demonstra intencionalidade inicial. \\
\hline & $1.3-O$ texto é claro em sua intencionalidade. \\
\hline \multirow{3}{*}{ II- Situacionalidade } & 2.1 - O texto não é relevante ao contexto de sua produção. \\
\hline & 2.2 - O texto apresenta uma relevância parcial. \\
\hline & 2.3 - O texto é relevante ao contexto de produção. \\
\hline \multirow{3}{*}{ III - Aceitabilidade } & 3.1 - O texto não reflete a preocupação do autor em ser claro para os leitores. \\
\hline & 3.2 - O texto traz uma preocupação parcial do autor em ser claro para os leitores. \\
\hline & 3.3 O texto reflete a preocupação do autor em ser claro para os leitores. \\
\hline \multirow{3}{*}{ IV - Não-contradição } & 4.1 - O texto apresenta muitas contradições. \\
\hline & 4.2 - O texto apresenta contradições esporádicas. \\
\hline & 4.3 - O texto não apresenta contradições. \\
\hline \multirow{3}{*}{ V - Repetição } & $\begin{array}{l}5.1 \text { - O texto não apresenta repetições bem coordenadas (o autor não faz bom uso de } \\
\text { elementos coesivos.). }\end{array}$ \\
\hline & 5.2 - O texto apresenta parcialmente o uso de elementos coesivos. \\
\hline & 5.3-O texto apresenta mecanismos coesivos sempre que necessário. \\
\hline \multirow{3}{*}{ VI - Progressão } & 6.1 - O texto não apresenta progressão, sendo repetitivo ao extremo. \\
\hline & $\begin{array}{l}\text { 6.2 - O texto apresenta progressão parcial, apresentando algumas repetições } \\
\text { desnecessárias. }\end{array}$ \\
\hline & $\begin{array}{l}\text { 6.3 - O texto apresenta progressão total, com significados novos e sem repetições } \\
\text { desnecessárias. }\end{array}$ \\
\hline \multirow{3}{*}{$\begin{array}{l}\text { VII - Continuidade } \\
\text { ou relação }\end{array}$} & $\begin{array}{l}7.1 \text { - Há um esboço de eventos ou fatos sem que seja definido o principal ou uma ligação } \\
\text { entre eles. }\end{array}$ \\
\hline & 7.2 - Há vários eventos com alguma relação entre si, sem definição do principal condutor. \\
\hline & 7.3 - Há uma relação clara entre os eventos, um fio condutor e evento principal. \\
\hline
\end{tabular}

Figura 1- Níveis de textualidade de Lubian (2007) 
Além dessas coletas, houve uma entrevista, aplicada individualmente, com os alunos sobre práticas de letramento vivenciadas por eles.

Todos os procedimentos de coleta da presente pesquisa foram realizados pela mestranda responsável pelo trabalho e orientados por professora com prática em aprendizagem.

A presente pesquisa está vinculada ao projeto "Clínica da linguagem escrita: práticas de letramento e gêneros textuais", com registro e aprovação no comitê de ética em pesquisa institucional no. 0139.0.243.000-07.

Os resultados das análises das entrevistas e dos textos foram comparados, qualitativamente, inter e intragrupo. Os resultados relativos à forma e níveis textuais foram analisados quantitativamente, também inter e intragrupos.

A análise estatística dos dados foi realizada mediante os seguintes testes estatísticos: Fisher, Wilcoxon e Qui-quadrado, selecionados de acordo com a necessidade de cada comparação efetivada, utilizando-se nível de significância inferior a $0,05(5 \%)$.

\section{RESULTADOS}

A seguir são apresentadas as tabelas que resumem os resultados da compreensão textual (Tabela 1), desempenho textual (Tabelas 2 e 3) e práticas de letramento familiar (Tabela 4).

Conforme pode-se perceber na Tabela 1, não há diferença estatística entre os grupos de estudo e controle, em ambas as séries, na habilidade de compreensão textual. Os sujeitos demonstram a capacidade de compreender questões mais objetivas sobre o texto de modo semelhante, embora o grupo de estudo apresente desempenho ligeiramente inferior, principalmente na quarta série.

Ressalte-se que as questões 4 e 5 , em ambos os textos utilizados, apresentavam a necessidade de resposta dissertativa. As questões 05 (quarta série) e 06 (quinta série) demandavam uma reflexão mais geral sobre o texto, mas em níveis de complexidade distintos. O texto de quinta série apresentou-se muito mais acessível do que o texto de quarta série, sobretudo nas últimas questões. A questão 04 do texto de quarta série, a qual demandava uma interpretação semântica de uma expressão (in natura), foi a de menor número de acertos (3 em 28).

Analisando resultados da Tabela 2, pode-se observar que há uma diferença de desempenho estatisticamente significante para as categorias aceitabilidade, repetição, intencionalidade e progressão, no texto autobiográfico, e para as categorias intencionalidade, situacionalidade, aceitabilidade e repetição no texto sobre violência. Esse dado sugere que as categorias aceitabilidade e repetição são as categorias que mais identificam diferenças entre sujeitos com queixa de dificuldades na escrita e os sujeitos sem tal queixa.

Os resultados também indicam que um mesmo grupo pode ter desempenho distinto quando se mudam as condições de produção, pois, por mais que se tenha controlado para solicitar a produção textual a partir de temáticas conhecidas pelos sujeitos, há evidências do comportamento distinto entre ambos os textos (autobiográfico e sobre violência). O primeiro com pior desempenho na progressão e o segundo, na situacionalidade e intencionalidade.

Outro aspecto a ressaltar é que a média 1,0, obtida em muitas categorias, pode ser assumida como baixa quando se considera que são sujeitos frequentando a quarta série e esse fato é comum a ambos os grupos.

$\mathrm{Na}$ Tabela 3, pode-se perceber que apenas os itens aceitabilidade e progressão, na produção autobiográfica, apresentaram diferença estatisticamente significante, demonstrando uma certa evolução na produção textual dos sujeitos da quarta para a quinta série.

Tabela 1 - Número de acertos na Compreensão Textual na $4^{a}$ e $5^{a}$ série

\begin{tabular}{|c|c|c|c|c|c|c|}
\hline & \multicolumn{2}{|c|}{$4^{a}$ série $n=28$} & \multirow{2}{*}{$\mathbf{P}$} & \multicolumn{2}{|c|}{$5^{a}$ série $n=14$} & \multirow{2}{*}{$\mathbf{P}$} \\
\hline & GC & GE & & GC & GE & \\
\hline Questão 1 & 13 & 13 & 1,000000 & 6 & 7 & 0,654721 \\
\hline Questão 2 & 11 & 5 & 0,053632 & 6 & 6 & 0,654721 \\
\hline Questão 3 & 10 & 7 & 0,334595 & 4 & 7 & 0,179713 \\
\hline Questão 4 & 1 & 2 & 0,747730 & 4 & 4 & 1,000000 \\
\hline Questão 5 & 7 & 3 & 0,168071 & 5 & 4 & 0,654721 \\
\hline Questão 6 & -------------- & ------------ & ------------ & 1 & 6 & 0,032125 \\
\hline
\end{tabular}

Em negrito dados estatisticamente significantes; variáveis analisadas mediante o Teste de Fisher

Rev. CEFAC, São Paulo 
Tabela 2 - Análise do desempenho em produção textual da 4ª série comparando GC e GE

\begin{tabular}{|c|c|c|c|c|c|c|c|c|}
\hline \multirow{2}{*}{$n=28$} & \multicolumn{2}{|c|}{ Média por Grupo } & \multirow{2}{*}{ Média } & \multirow{2}{*}{ Mediana } & \multirow{2}{*}{ Moda } & \multirow{2}{*}{$\begin{array}{l}\text { Freq. } \\
\text { da } \\
\text { Moda }\end{array}$} & \multirow{2}{*}{$\mathbf{P}$} & \multirow{2}{*}{$\begin{array}{l}\text { Desvio } \\
\text { Padrão }\end{array}$} \\
\hline & GC & GE & & & & & & \\
\hline B - Intencionalidade & 2 & 1,42 & 1,714 & 2 & 2 & 17 & 0,048184 & 0,659 \\
\hline B - Situacionalidade & 2 & 1,35 & 1,741 & 2 & 2 & 15 & 0,072580 & 0,712 \\
\hline B - Aceitabilidade & 2 & 1,35 & 1,679 & 2 & 2 & 18 & 0,015855 & 0,612 \\
\hline B - Não-contradição & 2,57 & 1,85 & 2,357 & 3 & 3 & 14 & 0,290605 & 0,780 \\
\hline B - Repetição & 1,57 & 1,07 & 1,321 & 1 & 1 & 17 & 0,038674 & 0,548 \\
\hline B - Progressão & 1,35 & 1 & 1,393 & 1 & 1 & 16 & 0,005836 & 0,629 \\
\hline B - Continuidade & 1,35 & 1,42 & 1,179 & 1 & 1 & 21 & 0,135360 & 0,476 \\
\hline V- Intencionalidade & 2 & 1,28 & 1,714 & 2 & 2 & 17 & 0,048184 & 0,659 \\
\hline V - Situacionalidade & 1,92 & 1,21 & 1,571 & 2 & 1 & 13 & 0,021598 & 0,742 \\
\hline V - Aceitabilidade & 1,85 & 1 & 1,519 & 2 & 2 & 15 & 0,004885 & 0,580 \\
\hline V - Não-contradição & 2,28 & 1,85 & 2,071 & 2 & 2 & 19 & 0,154338 & 0,663 \\
\hline V - Repetição & 1,57 & 1 & 1,286 & 1 & 1 & 18 & 0,016882 & 0,535 \\
\hline V - Progressão & 1,14 & 1,21 & 1,214 & 1 & 1 & 20 & 0,945052 & 0,499 \\
\hline V - Continuidade & 1,35 & 1 & 1,143 & 1 & 1 & 22 & 0,069535 & 0,448 \\
\hline
\end{tabular}

$\mathrm{B}$ = texto autobiográfico; $\mathrm{V}=$ texto violência; em negrito dados estatisticamente significantes; variáveis analisadas mediante o Teste de Fisher.

Tabela 3 - Análise do desempenho em produção textual da 5ª série comparando GC e GE

\begin{tabular}{|c|c|c|c|c|c|c|c|c|}
\hline \multirow{2}{*}{$n=14$} & \multicolumn{2}{|c|}{ Média por Grupo } & \multirow{2}{*}{ Média } & \multirow{2}{*}{ Mediana } & \multirow{2}{*}{ Moda } & \multirow{2}{*}{$\begin{array}{l}\text { Freq. } \\
\text { da } \\
\text { Moda }\end{array}$} & \multirow{2}{*}{$\mathbf{P}$} & \multirow{2}{*}{$\begin{array}{l}\text { Desvio } \\
\text { Padrão }\end{array}$} \\
\hline & GC & GE & & & & & & \\
\hline B - Intencionalidade & 2 & 1,28 & 1,643 & 2,0 & 2 & 8 & 0,073639 & 0,745 \\
\hline B - Situacionalidade & 2 & 1,28 & 1,643 & 2,0 & 2 & 8 & 0,073639 & 0,745 \\
\hline B - Aceitabilidade & 1,85 & 1 & 1,429 & 1,5 & 2 & 7 & 0,021451 & 0,646 \\
\hline B - Não-contradição & 2,42 & 1,57 & 2,000 & 2 & 2 & 7 & 0,096699 & 0,877 \\
\hline B - Repetição & 1,57 & 1 & 1,286 & 1 & 1 & 8 & 0,125202 & 0,611 \\
\hline B - Progressão & 1,85 & 1 & 1,429 & 1,5 & 2 & 7 & 0,021451 & 0,646 \\
\hline B - Continuidade & 1,28 & 0,85 & 1,071 & 1 & 1 & 11 & 0,224800 & 0,475 \\
\hline V - Intencionalidade & 2 & 1,28 & 1,643 & 2 & 2 & 8 & 0,110224 & 0,745 \\
\hline V - Situacionalidade & 1,57 & 1,28 & 1,500 & 2 & 2 & 8 & 0,306686 & 0,650 \\
\hline V - Aceitabilidade & 1,57 & 1,42 & 1,500 & 2 & 2 & 8 & 0,848006 & 0,650 \\
\hline V - Não-contradição & 2 & 1,71 & 1,857 & 2 & 2 & 7 & 0,654721 & 0,864 \\
\hline V - Repetição & 1,28 & 1 & 1,0 & 1,0 & 1 & 10 & 0,443289 & 0,535 \\
\hline V - Progressão & 1,42 & 1 & 1,214 & 1,0 & 1 & 9 & 0,250154 & 0,579 \\
\hline V - Continuidade & 1,42 & 1 & 1,231 & 1,0 & 1 & 8 & 0,283978 & 0,599 \\
\hline
\end{tabular}

$\mathrm{B}=$ texto autobiográfico; $\mathrm{V}=$ texto violência; em negrito dados estatisticamente significantes; variáveis analisadas mediante o Teste de Fisher.

Outra análise implementada, não exposta em tabelas, foi a comparação estatística entre os desempenhos de ambos os tipos de textos. Pode-se observar que, apesar das diferenças específicas a cada tipo em cada série, a aplicação do teste de Wilcoxon, o qual permite avaliar o mesmo indivíduo em duas condições distintas, na comparação geral entre os desempenhos grupais nos dois tipos de produção, demonstra que as produções textuais autobiográficas e sobre violência não apresentaram diferença estatisticamente significante entre elas ( $p>0,05$ em todas as comparações).

Comparando-se os resultados de quarta e quinta séries, observam-se médias abaixo do esperado para o nível escolar, pois há pouca evolução entre as mesmas e o nível 2 ainda é pouco presente e o nível 3 praticamente ausente. 
A inexistência de diferenças estatisticamente significantes entre as práticas de letramento, visualizada na Tabela 4, demonstra que os sujeitos estão expostos a um mesmo perfil familiar. Em relação à função da escrita, esta se relaciona à obtenção de conhecimento e de melhores perspectivas laboriais, mas, poucas vezes, é mencionada como hábito de lazer. Já em termos de tipos de materiais, o acesso a livros, revistas e jornais parece predominar. Os livros são mais buscados na biblioteca escolar, enquanto jornais e revistas estão acessados pela família em casa.
A frequência de leitura quinzenal é a maior, seguida da diária e semanal. Cabe observar que, em um $\mathrm{n}$ de 42 pais, apenas 14 responderam esta questão, sugerindo que os outros 28 não possuem o hábito de ler.

É possível afirmar que há práticas familiares insuficientes para um bom modelo educacional em leitura e escrita para todos os sujeitos (GE e GC). Esse fato talvez explique que os pais pouco ajudam nas tarefas escolares. Muitas vezes, esta função é deixada para irmãos mais velhos.

Tabela 4 - Práticas de letramento vivenciadas pelos alunos e seus pais

\begin{tabular}{|c|c|c|c|c|c|c|c|c|c|c|c|}
\hline & & \multicolumn{5}{|c|}{ PAIS } & \multicolumn{5}{|c|}{ CRIANÇAS } \\
\hline & & \multicolumn{2}{|c|}{$4^{a}$ série } & \multicolumn{2}{|c|}{$5^{a}$ série } & \multirow{2}{*}{$\mathbf{P}$} & \multicolumn{2}{|c|}{$4^{a}$ série } & \multicolumn{2}{|c|}{$5^{\mathrm{a}}$ série } & \multirow{2}{*}{$\mathbf{P}$} \\
\hline & & GC & GE & GC & GE & & GC & GE & GC & GE & \\
\hline \multirow{3}{*}{$\begin{array}{l}\text { Função da } \\
\text { Escrita }\end{array}$} & Trabalho & 2 & 2 & 0 & 0 & \multirow{3}{*}{ * } & 2 & 4 & 2 & 4 & \multirow{3}{*}{0,6451} \\
\hline & Conhecimento & 10 & 12 & 7 & 7 & & 12 & 10 & 5 & 3 & \\
\hline & Lazer & 2 & 0 & 0 & 0 & & 0 & 0 & 0 & 0 & \\
\hline \multirow{4}{*}{$\begin{array}{l}\text { Tipo de } \\
\text { Portador de } \\
\text { Texto }\end{array}$} & Nada & 1 & 1 & 0 & 0 & \multirow{4}{*}{ * } & 0 & 0 & 0 & 0 & \multirow{4}{*}{0,7036} \\
\hline & Livros & 4 & 7 & 3 & 2 & & 2 & 4 & 0 & 0 & \\
\hline & Livros/ Jornais & 5 & 4 & 4 & 4 & & 12 & 9 & 1 & 1 & \\
\hline & $\begin{array}{c}\text { Livros/Revistas/ } \\
\text { Jornais }\end{array}$ & 4 & 2 & 0 & 0 & & 0 & 1 & 6 & 6 & \\
\hline \multirow{4}{*}{$\begin{array}{l}\text { Frequência } \\
\text { de Leitura }\end{array}$} & Outro & 4 & 3 & 0 & 1 & & & & & & \multirow{4}{*}{ * } \\
\hline & Diária & 2 & 2 & 6 & 1 & & & & & & \\
\hline & Semanal & 3 & 2 & 1 & 3 & & & & & & \\
\hline & Quinzenal & 5 & 7 & 0 & 2 & & & & & & \\
\hline \multirow{2}{*}{$\begin{array}{l}\text { Participação } \\
\text { dos Pais na } \\
\text { Vida Escolar } \\
\text { dos Filhos }\end{array}$} & Sim & 12 & 2 & 7 & 6 & \multirow{2}{*}{0,5956} & & & & & \multirow[b]{2}{*}{ * } \\
\hline & Não & 13 & 1 & 0 & 1 & & ----- & ----- & ----- & ------ & \\
\hline
\end{tabular}

* dados não testáveis estatisticamente em função do n; variáveis analisadas mediante o Teste Qui-quadrado.

\section{DISCUSSÃO}

Em relação à compreensão textual, os resultados da presente pesquisa demonstram que, em ambas as séries, o desempenho geral não foi satisfatório, não apresentando diferença da quarta para a quinta série. Tal fato demonstra a falta de evolução de uma série para outra. Há estudos que afirmam que tal compreensão não é enfocada ou não é bem avaliada por não ser tão visível quanto a produção ${ }^{20}$. Esse desempenho preocupa quando se sabe que ler bem é fundamental para o processo de aquisição da escrita.

Chama atenção o desempenho ruim na questão número 4 , do questionário da quarta série. Possivelmente, o mesmo ocorra porque trazia uma expressão em latim, in natura, o que exigiu das crianças a capacidade de pensar sobre a linguagem, ou seja, a capacidade de metalinguagem ${ }^{7,23}$. $\mathrm{O}$ baixo desempenho dos sujeitos nessa questão pode ser explicado em função do perfil cultural dos sujeitos e seus familiares, uma vez que o baixo nível de letramento acarreta pouca possibilidade de reflexão sobre a linguagem em si ${ }^{24}$.

Outro tipo de questão problemática para os sujeitos foram a questão 5 , da quarta série, e a questão 6 , da quinta série. Por serem opinativas, elas demandavam dos sujeitos uma conclusão a partir de uma reflexão global do texto. O baixo desempenho dos alunos nessas questões sugere que estes não conseguem transcender aspectos complexos do texto para formar uma opinião. Já a questão 5 da quinta série exigia que os sujeitos apresentassem atenção e realizassem um raciocínio 
inferencial com base no texto. O pouco número de acertos nessa questão demonstra uma possível desatenção do alunos ao respondê-la ${ }^{15}$.

Em relação ao desempenho textual, embora não haja diferença estatisticamente significante entre ambas as produções, os textos autobiográficos apresentaram mais níveis alterados do que as produções sobre violência. $O$ item aceitabilidade, relacionado à forma, apresentou baixos escores gerais, fato que pode ser explicado, em parte, pelas poucas práticas de letramento apresentadas pelos sujeitos. Por outro lado, pode-se inferir que o baixo nível de compreensão textual esteja ocupando grande parte do processamento do texto, de modo a não permitir a memorização de aspectos gráficos em ambas as séries. Sabe-se que a reflexão sobre aspectos formais demanda uma certa liberação da memória operacional durante o processamento do texto. Uma terceira hipótese seria o fato de o professor não estar fazendo a reflexão necessária sobre aspectos formais em sala de aula como afirmam alguns autores ${ }^{25}$.

Quanto à progressão, a qual caracteriza-se pela informatividade crescente do texto, explicitada pelo acréscimo de informações novas no decorrer da produção textual, o falar em si e refletir sobre si mostrou-se difícil para os sujeitos da pesquisa, o que demonstra uma falta de prática na produção de textos por parte dos sujeitos. Esperar-se-ia que os sujeitos de quinta série apresentassem um desempenho melhor nesse item do que os sujeitos de quarta série, mas isso não ocorreu.

Em relação à repetição, que é o uso de elementos coesivos para que o texto não se torne repetitivo ao extremo, os sujeitos da quarta série ainda não dominam este aspecto porque este surge mais tarde na aprendizagem dos sujeitos, fato que se comprova com os resultados apresentados na quinta série ${ }^{26}$. Sabe-se, no entanto, que este não é um aspecto muito enfatizado nas correções textuais em sala de aula ${ }^{6}$ porque demandaria a re-escrita do texto e correção detalhada por parte do professor. Observa-se, em geral, que o foco da exigência do professor é a ortografia ${ }^{7}$ sem que haja um trabalho reflexivo também nesse aspecto ${ }^{25}$. Tais observações se confirmaram neste estudo, demonstrando que os sujeitos estão em um domínio da coesão e da ortografia inferior ao esperado para sua faixa etária ${ }^{21}$.

Os itens intencionalidade e situacionalidade se apresentaram alterados na produção sobre violência porque, apesar de ser um tema debatido em sala de aula pelo professor, talvez os sujeitos ainda não tivessem uma intenção clara sobre o que dizer, saindo, por vezes, fora do tema. Mesmo vivendo em situação de risco social e estando mobilizados pelo Caso Isabela, não havia ainda as condições de produção necessárias para que houvesse uma intenção comunicativa clara. Esse dado reforça a importância de a produção textual ser antecedida por leituras e discussões sobre o tema proposto e posteriores re-escritas do texto ${ }^{27}$.

Os dados de letramento familiar não parecem justificar as diferenças encontradas entre os grupos, o que direciona a questão para aspectos pedagógicos e/ou intrínsecos aos sujeitos (verdadeiros distúrbios de base orgânica) ${ }^{28}$. Sustentam, no entanto, que há um desempenho pobre, em geral, para todos os grupos em compreensão e produção textuais. Nesse caso, a escola deveria suprir tal déficit, provendo as condições de acesso à cultura letrada de modo suficiente para o desenvolvimento do grupo. Os dados de compreensão textual sugerem que isso pode não estar ocorrendo. Eles também indicam que condições intrínsecas dos sujeitos não estão influenciando de modo geral todos itens avaliados, já que há evoluções entre quarta e quinta série. Além disso, acredita-se que se os sujeitos da pesquisa apresentassem distúrbios orgânicos, como a dislexia, por exemplo, haveria uma certa regularidade de alteração em todos os itens, produzindo diferenças estatísticas em outros níveis textuais, além dos encontrados.

O baixo desempenho nos itens aceitabilidade (forma) e progressão (conteúdo) demonstram que o cerne da produção textual continua sem progresso importante de quarta para quinta série, sendo que são itens que diferenciam o Grupo de Estudo e o Grupo Controle, mas não são suficientes para afirmar uma alteração de linguagem intrínseca ao sujeito nesta pesquisa.

Como parece haver progresso espontâneo dos sujeitos de quarta para quinta série, pode-se sugerir que as alterações apresentadas pelos sujeitos não são de base orgânica, mas podem representar limitações pedagógicas ${ }^{29-32}$.

\section{CONCLUSÃO}

Houve diferença estatisticamente significante entre grupo controle e de estudo em algumas categorias textuais, sobretudo aceitabilidade e progressão. De um modo geral, ambos os grupos apresentaram desempenhos textuais abaixo do esperado para sua escolaridade, sobretudo na compreensão, fato que parece estar relacionado a práticas de letramento insuficientes tanto na escola como no ambiente familiar.

Vale ressaltar ainda, a necessidade de mais pesquisas dentro da fonoaudiologia utilizando o texto como unidade de análise e de intervenção na terapêutica das dificuldades de linguagem escrita. 


\section{ABSTRACT}

Purpose: compare the textual performance of production and the reading comprehension of students in fourth and fifth grade of elementary school, with and without complaints of desabilities in the writing language, relating them with the practices of literacy experienced by these students. Methods: 21 were assessed pre-adolescents in 4th and 5th grade of public schools, with complaint of desability in writing language and 21 controls in the same classroom, on the textual production, textual comprehension and practices of literacy. The textual productions were evaluated following the protocol of textual levels. Results: there isn't statistical difference between the study groups and control in both grades in the ability textual understanding. Regarding the textual production in the 4th grade the items that showed changes were: situational, acceptability, repetition, progression, and intentionality. Already in the 5th grade, the items changed to acceptability and progress. All subjects had insufficient practice of literacy. Conclusion: there was a statistical difference between the control group and the study in some textual categories, particularly acceptability and progress. In general, both groups were lower than expected textual performance for your schooling, a fact that seems to be related to inadequate practices of literacy as much in the school as the family environment.

KEYWORDS: Learning Disorders; Reading; Learning Disorders.

\section{REFERÊNCIAS}

1. Reimers F. La buena enseñanza y el éxito escolar de los estudiantes en América Latina. Rev Iberoam Educ. 2003; 31:17-48.

2. Berberian AP, Mori-de Angelis CC, Massi G. Violência simbólica nas práticas de letramento. In: Berberian AP, Mori-de Angelis CC, Massi G. Letramento: referenciais em saúde e educação. São Paulo: Plexus; 2006.

3. Perrota C, Masini L, Märtz MLW. O trabalho terapêutico fonoaudiológico com a linguagem escrita: considerações sobre a visitação a gêneros discursivos. Dist Comun. 2004; 16(2):181-93.

4. Salles JF de, Parente MAMP. Avaliação de leitura e escrita de palavras em crianças de $2^{2}$ série: abordagem neuropsicológica cognitiva. Psicol Reflex Crít. 2007; 20(2):220-228.

5. Salles JF de, Parente MAMP. Variabilidade no desempenho em tarefas neuropsicológicas entre crianças de $2^{\text {a }}$ série com dificuldades de leitura e escrita. Arq Bras Psicol. 2008; 60(1):32-44.

6. Santos GRB dos. Avaliação de redações nas séries iniciais: frase ou texto como limite? [dissertação] Passo Fundo (RS): Universidade de Passo Fundo; 2007.

7. Capovilla AGS, Dias NM, Montiel JM. Desenvolvimento dos componentes da consciência fonológica no ensino fundamental e correlação com nota escolar. Psico-UFS. 2007; 12(1):55-64.

8. Salles JF de, Parente MAMP. Heterogeneidade nas estratégias de leitura/escrita em crianças com dificuldade de leitura e escrita. Psico PUCRS. 2006; 37(1):83-90.

9. Munhoz CMA, Massi G, Berberian AP, Giroto CRM, Guarinello AC. Analysis of the speech and language national scientific production on written language. Pró-Fono. 2007; 19(3):249-58.

10. Barcellos CAP, Freire RM. Assessoria fonoaudiológica na escola: sob o efeito da escrita e sua aquisição. Dist Comun. 2005; 17(3):373-83.

11. Trenche $M C B$, Balieiro $C R$. Da escrita á fala: indícios da presença da escrita no discurso da criança surda. Dist Comun. 2006; 18(1):95-102.

12. Maia SM, Serapompa MT. Acolhimento e inclusão: da clínica ao acompanhamento escolar de um sujeito com Síndrome de Down. Dist Comun. 2006; 18(3):313-22.

13. Marcolino J, Catrini M. O jogo entre fala/ escrever/ler na clínica de linguagem com afásicos. Dist Comun. 2006; 18(1):103-9.

14. Bakhtin M. Os gêneros do discurso. Estética da criação verbal. São Paulo: Martins Fontes; 2003. p. 261-306.

15. Goulart C. Letramento e modos de ser letrado: discutindo a base teórico-metodológica de um estudo. Rev Bras Educ. 2006; 11(33):540-2.

16. Corrêa MC. Representações de escrita: esse obscuro objeto do desejo. Cad Pesq Lingüíst. 2005; $1(1): 47-50$.

17. Souza LV, Moulin MF, Costa SS. As contribuições do interacionismo sociodiscursivo para o letramento escolar. Calidoscópio. 2004; 2(2):61-6.

18. Carvalho MP. Sucesso e fracasso escolar: uma questão de gênero. Educ Pesq. 2004; 29(1):185-93. 
19. Carvalho MP. Quem são os meninos que fracassam na escola? Cad Pesq. 2004; 34(121):11-40.

20. Lubian ME. Processo de produção textual em uma proposta transdisciplinar na $4^{\mathrm{a}}$ série do ensino fundamental. [dissertação] Passo Fundo (RS): Universidade de Passo Fundo; 2007.

21.Salles J.F de, Parente MAMP. Relação entre o desempenho infantil em linguagem escrita e a percepção do professor. Cad Pesq. 2007; 37(132):687-709.

22. Koch IGV, Travaglia LC. A coerência textual. São Paulo: Contexto; 2003. 94p.

23. Santos MTM dos, Navas ALGP. Distúrbios de leitura e escrita: teoria e prática. Barueri: Manole; 2002.

24. Paula GR, Mota HB, Keske-Soares M. A terapia em consciência fonológica no processo de alfabetização. Pró-Fono. 2005; 17(2):175-84.

25. Morais AG de. Ensino de ortografia: como vem sendo feito? Como transformá-lo? Projeto: revista de educação. 1999; 1: 4-9.
26. Guimarães AMM. O desenvolvimento da coesão: estratégias da passagem do contexto ao texto. [tese]. Porto Alegre (RS): Pontifícia Universidade Católica do Rio Grande do Sul; 1990.

27. Geraldi JW. Portos de Passagem. 3. ed. São Paulo: Martins Fontes; 1995.

28. Etchepareborda MC, Habib M. Bases neurobiológicas de la conciencia fonológica: su compromiso en la dislexia. Rev Neurol Clin. 2001; 2(1): 5-23.

29. Lozano A, Ramírez M, Ostroskysolís F. Neurobiología de la dislexia del desarrollo: una revisión. Rev Neurol. 2003; 36(11):1077-82.

30. Artigas-Pallarés J. Problemas associados a la dislexia. Rev Neurol. 2004; 34(1):7-13.

31. Galaburda AM, LoTurco J, Ramus F, Fitch RH, Rosen GD. La dislexia del desarollo: gen, cerebro y cognición. Psykhe. 2006; 15(2):3-11.

32. López-Escribano C. Contribuiciones de la neurociencia al diagnótico y tratamiento educativo de la dislexia del desarollo. Rev Neurol. 2007; 44(3):173-80.

RECEBIDO EM: 04/04/2009

ACEITO EM: 28/07/2009

Endereço para correspondência:

Vanessa Deuschle-Araújo

Rua Pinheiro Machado, 396, centro

São Francisco de Assis - RS

CEP: 97610-000

E-mail: deuschlefono@gmail.com 